\title{
LA PSICOHISTORIA: MÉTODO DE ENSEÑANZA, MÉTODO DE INVESTIGACIÓN
}

\author{
Hugo Torres Salazar ${ }^{1}$
}

\begin{abstract}
«...no se conquistan nunca espíritus, no se vence nunca a hombres, no se sustituye nunca una doctrina por otra sin dejar fatalmente que otro espíritu invada nuestro espíritu, otro hombre penetre nuestra humanidad, otras doctrinas se inserten en nuestra doctrina.
\end{abstract}

Lucien Febvre. «Martín Lutero: un destino» (Breviarios. México: FCE, 1992).

(Recibido el 07/08/2006, aceptado el 06/10/2006)

Hoy en nuestros días, quien desee profundizar dentro de una nueva visión de lo que es historia, tiene que comprender la historia de nuestro entorno en su perspectiva geológica, ecológica, biológica y psicológica; es mediante la integración de todos esos aspectos que la historia se hace sustancial, fundamental y consecuente. Pero, sobre todo, quizá nos lleve a la historia que exige nuestro momento actual: a una historia total del hombre y de sus productos culturales.

Esto posibilitó que a partir de los años 60 del siglo XX, surgiera una herramienta dentro de la historiografía; para comprender el valor del contexto histórico en su influencia en el comportamiento, se estructuró la Psicohistoria como una orientación teórica que se centra en el análisis psicológico de hechos históricos de personas, colectivos o fenómenos sociales.

La psicohistoria es una herramienta que ha surgido de la necesidad de combinar el trabajo de dos teorías; la historia y el psicoanálisis, en la tarea del conocimiento de leyes que rigen el universo y más particularmente de aquellos que rigen el comportamiento; la idea es comprender el pasado a través de la determinación psíquica inconsciente de todas las acciones y de todas las inacciones humanas que constituyen la historia.

La historia iluminada por la tradición freudiana en el psicoanálisis, aspira a esclarecer las motivaciones humanas inconscientes tras las acciones históricas conscientes, impactadas por los conflictos internos que afectan a la psique individual.

Con la psicohistoria se plantea la posibilidad de establecer relaciones entre los fenómenos históricos y psicológicos; lo cual posibilita no sólo hacer comparaciones históricas y sociales,

1 Doctor en Historia. Universidad «Paul Valéry». Montpellier, Francia. Profesor e Investigador. Departamento de Historia. Centro Universitario de Ciencias Sociales y Humanidades. Universidad de Guadalajara. México. Psicoanalista Titular, Asociación Psicoanalítica Mexicana, A. C. E-mail: htorres@cencar.udg.mx 
sino también el análisis de sistemas o variables psicológicas; la idea es formular hipótesis entre las posibles interacciones entre estructura social y mecanismos psicológicos.

Por su énfasis en plantear explicaciones psicológicas en la historia de la persona, es más recurrente la escritura de psicobiografías.

Aún cuando en la obra de Freud no constara expresamente el término de psicohistoria, lo cierto es que podemos reconocerlo en trabajos significativos de Freud, por ejemplo, en su estudio biográfico de 1910 sobre Leonardo, titulado «Un recuerdo infantil de Leonardo da Vinci» en donde se pretende reconstruir la biografía del personaje a partir del trasfondo homosexual de su carácter; o también en la biografía que Freud escribiera, en colaboración con William Bullit, sobre el presidente estadounidense Wilson, en donde pretende demostrar la influencia que sobre el curso de la historia puede llegar a tener la personalidad de un gran personaje público.

El vocablo psicohistoria aparece por primera vez en un contexto claramente psicoanalítico. Pierce L. Clark publicó en 1924 un tratado sobre la sexualidad en el arte griego, titulado $A$ psychohistorical study of sex balance in Grek art, en donde aparece ya por primera vez el término psicohistoria; poco después, este mismo autor escribe otro trabajo en donde utiliza el calificativo de psicohistoria, explícito en el título A psychohistorical study of Akhnaton, first idealist and originator of monotheistic religión.

Para los años 70', el psicoanalista norteamericano Erik H. Erikson, le da un gran aporte a la psicohistoria con sus trabajos sobre Lutero y Gandhi. En El joven Lutero y La verdad sobre Gandhi, Erikson sustenta que al comprender al gran hombre comprendemos también a sus seguidores y sus motivaciones, conscientes e inconscientes. El gran hombre es para Erikson, el vocero de las tensiones de su tiempo, las cuales remedia desde la resolución de sus propias crisis. El gran hombre termina asumiendo las ansiedades y demandas de las masas de su época, a las cuales contribuye a elevar y transformar.

En la prolija crónica del psicoanálisis que Peter Gay hace, se da la oportunidad de ejercer la psicohistoria, en donde revela lo que Freud tal vez quiso ocultar; sus odios y preferencias, sus «traumas indispensables» y la recurrente depresión. También retrata el cariz de sus colaboradores, desde el inestable Ferenczi al mediocre Jones. Y en fin, el amor fervoroso por Ana, la hija que lo acompañó en sus últimos años y lo impuso definitivamente en el mundo anglosajón.

En esta obra Gay, esculpió a Freud en su amplio contexto cultural y científico, con sus méritos y con sus rencores. Acepta que el creador del psicoanálisis navegó por tres caudalosas corrientes: el racionalismo crítico, la cultura alemana, y el judaísmo; además, nos da la oportunidad de ver a Freud no sólo como un genio, sino como un profeta iracundo, un anciano prudente y un hombre agradable.

A la vista de estos datos, pudiera pensarse que la psicohistoria es ante todo una tarea característicamente psicoanalítica, una especie de consecuencia lógica de la metodología del psicoanálisis instaurada por Freud. Y esto puede ser considerado como válido, pero no totalmente ya que pueden afrontarse estos tipos de estudios, denominados psicohistóricos, desde otras vertientes o teorías sociales que no sólo se distancian del psicoanálisis sino aún están en conflicto con ella. 
«A poco que se mire, cabe apreciar que el psicoanálisis no tiene exclusividad ni monopolio en los problemas reconocidos como psicohistóricos, ya que, en efecto, en el ámbito de las ciencias humanas y de la filosofía antropológica existe una notable variedad de enfoques o aproximaciones de las cuales pudiera decirse que cada uno, a su modo, afronta e incide en el estudio e investigación de ese tipo de problemas. Este sería el caso, por ejemplo, de la filosofía antropológica o social que han puesto en juego algunos autores pertenecientes a la denominada «Escuela de Frankfort», tales como Hankheimer, Fromm, Marcuse, Reich, Elias, cuyos intentos de síntesis freudomarxista hicieron en sus trabajos.

La estrategia de hacer historia con explicaciones psicológicas fue ensayada desde Michelet con su monumental Historia de Francia y particularmente con El Pueblo ${ }^{l}$, La Mujer y la heroína gala, Juana de Arco; hasta llegar a su cristalización con la obra de Lucien Febvre ${ }^{2}$. Estos autores se orientaron a reconstruir, a partir de determinadas situaciones históricas, los modos psicológicos como los individuos y los grupos pudieron haber vivido dichas situaciones, a la par que a intentar explicar la incidencia que dichas percepciones psicológicas pudieran a su vez haber tenido en la configuración o transformación del decurso histórico.

En Martín Lutero: un destino, Febvre escribe: «Primero, el doloroso cuadro de una infancia sin amor, sin alegría y sin hermosura. Lutero nacía, probablemente en 1483, un 10 de noviembre, víspera de San Martín, en la pequeña ciudad de Eisleben en Turingia. Regresó a morir allí sesenta y tres años más tarde. Sus padres eran pobres: el padre, un minero, duro consigo mismo, rudo con los demás; la madre, una mujer agotada y como aniquilada por su trabajo demasiado duro; buena cuando mucho para atiborrar de prejuicios y de supersticiones temerosas [a] un cerebro de niño bastante impresionable. Estos seres sin alegría criaban al pequeño Martín en un poblado, Mansfeld habitado por mineros y mercaderes» ${ }^{3}$.

También cabría reconocer que la «Arqueología del saber» puesta en juego por su autor MIchel Foucault, no estaría a la postre tan alejada del ámbito de las cuestiones de algún modo reconocibles como psicohistóricas, o, por otro lado, también incidirían en dicho ámbito el intento de «psicología cultural», ensayado por un autor como Kantor»"

A la vista de semejante panorama quizá ahora la pregunta que nos plantearíamos sería, cómo se estructura la Psicohistoria y cuáles serían los fenómenos para su estudio?

La psicohistoria surge como una vertiente dentro de la historiografía, acuñada alrededor de los años 60 en Estados Unidos e intenta analizar las motivaciones inconscientes que subyacen en las acciones tanto de los líderes como de las masas humanas; de ahí que el psicohistoriador traslada los qué y por qué de la historia a los porqué inconscientes.

Estas relaciones llevarían a los historiadores a utilizar estrategias históricas orientadas a ensayar un doble circuito conjugado entre las configuraciones histórico-culturales-objetivas y la participación de los sujetos-individuales en semejantes configuraciones; sería ahí, donde su psiquismo cobra fundamentalmente su figura; en lo colectivo, en lo social.

Esto no debe llevarnos a un simple reduccionismo de considerar las configuraciones históricas, o el histórico objetivo a una mera reducción del psiquismo de los individuos, sino a ver la incidencia o influencia que dicho psiquismo, modelado históricamente, pudiera tener a su vez en las transformaciones de las configuraciones históricas.

De ahí que el método de la psicohistoria permite desentrañar el fondo humano del problema, haciendo entrar en la historia algunos aspectos oscuros, no racionales, instintivos y 
emocionales de sus protagonistas, que normalmente escapan al discurso racional de la historia. Así lo pone de manifiesto Francisco Alonso-Fernández en su obra Historia personal de los Austrias españoles (Mexico: FCE, 2000).

Tomado de su obra, señala: «el emperador Carlos V de Alemania era un personaje de un gran valor humano, de un gran arranque, un gran coraje, una gran valentía, magnánimo con el vencido, flexible, nada dogmático, opuesto al cisma entre protestantes y católicos. Sin embargo, a los 40 años cambió completamente, abdicó en su hermano y su hijo, se retiró al monasterio de Yuste y se convirtió en un fanático, influyendo profundamente en su hijo Felipe II. Este cambio fundamentalmente en la historia de España estuvo causado por una depresión muy fuerte marcada por un gran sentimiento de culpa, por no haber acabado con el protestantismo».

De Felipe II, escribe «...un personaje no apto para tal responsabilidad, ya que, según Alonso-Fernández, «tenía una personalidad obsesiva y como consecuencia de esto era muy dubitativo, muy lento, parsimonioso, muy reducido en el espacio, además de supersticioso y fanático. Apenas viajo y era muy mal comunicador, algo que perjudicó mucho a España; se le llamaba el Rey Prudente, cuando en realidad lo único que hacía era dudar».

También los llamados Austrias menores, que reinaron durante el siglo XVII, tienen su diagnóstico: «Felipe III era ludópata y débil de personalidad; Felipe IV padecía dependencia emocional, principalmente del Conde Duque de Olivares y de la llamada Monja de Agreda y adicción al sexo, tuvo más de 30 hijos bastardos; y Carlos II, El Hechizado, parece ser que sufría el síndrome de Klineferler, es decir, tenía un cromosoma $X$ supernumerario, que le produjo una grave alteración sexual, un retraso mental e incluso crisis epilépticas; pero según el Inquisidor General, lo que sufría el rey era un hechizo».

Otro personaje estudiado por Alonso-Fernández es Francisco de Goya, y llegó a la conclusión de que padecía un trastorno bipolar: «A lo largo de su vida sufre 7 episodios de depresión, hasta que a los 40 años tiene un gran trastorno depresivo del que sale con un episodio hiperquímico. A partir de ahí empieza a pintar como él quiere pintar. Este trastorno se repetiría en 1820, cuando Goya tenía 70 años, durante su exilio voluntario en Burdeos; la depresión fue el origen de las pinturas negras y la posterior hiperquimia le convirtió en un personaje exultante, activo, resumiendo este período con perfección el dictamen del escritor Eugenio d Ors: 'Goya murió de alegría'».

Otro ejemplo lo tenemos en el estudio que sobre Salvador Allende, hizo la doctora Diana Veneros Ruiz-Tagle (Chile, marzo de 2003). Para escribir Salvador Allende Gossens: Anatomía de un liderazgo, Ruiz-Tagle recurrió a fuentes significativas que todo historiador que practique la psicohistoria, debe considerar; cartas, iconografía, memorias, epistolarios, testamentos, etcétera, material que en su investigación permitirá aprehender, describir y analizar las diferentes manifestaciones que el psiquismo de los protagonistas ha adoptado históricamente en las distintas configuraciones socioculturales.

Conforme a las evidencias, de acuerdo a Diana Veneros, «la vida temprana de Allende estuvo asociada al disfrute de un exceso de gratificación materna proveniente de las dos mujeres principales en su vida infantil y aún adulta: su bellísima y virtuosa madre, doña Laura Gossens Uribe -ferviente católica, mujer inteligente, enérgica y confiable- y su devota «Mamá Rosa», la mujer que dejó (como muchas otras) a su propia hija, para viajar con los Allende a Tacua, para hacerse cargo de Salvadorcito o «Chichito» como él se 
autodenominaba cuando era pequeño». Un motivo edípico asociado a estos nexos y afectos primarios, y la idealización de figuras femeninas maternales nutrientes y protectoras fue dominante a lo largo de la vida de Allende».

De su padre; escribe:....ante los ojos de su hijo, Allende Castro no calzaba con los heroicos ejemplares ancestros de la familia Allende. La rivalidad y el menosprecio inconscientes condujeron al joven Allende a reprimir cualquier identidad manifiesta con su padre».

De igual manera en el estudio que Hugo Torres hace sobre Frida Kahlo ${ }^{5}$, expresa; que «el dolor será para Kahlo el manantial y origen de su tragedia, creando desde la intersubjetividad un imperativo superyoico cruel y una facilitación para el masoquismo».

En la conclusión afirma que para Frida -como para cualquiera- serán decisivos sus años infantiles, su relación con su madre, con su padre y con su nana; los primeros encuentros y desencuentros con sus figuras de identificación, que constituirán las «matrices» de su psiquismo las cuales incidirán sobre la calidad de las experiencias de su vida. Y para fundamentar esto, cita: «la madre de Frida no pudo dar el pecho a ésta, pues ya once meses tras su llegada al mundo, nació su hermana Cristina [quien no sólo le quitó la madre, sino también a Diego]. Por eso fue alimentada por una nodriza. Esta relación la manifiesta en su cuadro que tituló «Mi nana y yo o Yo mamando», obra de 1937, donde la relación que expresa hacia la nana-mamá, da la impresión de ser distante, fría y reducida al acto práctico de la alimentación, una impresión que se ve acentuada por la carencia de contacto visual y la máscara que cubre el rostro de la nodriza».

De lo anterior podemos resumir que se pueden inferir supuestos de la vida de cualquier hombre o mujer, analizando las circunstancias familiares y las alternativas de su socialización en el desarrollo de su psiquismo; para esto podemos proponer el estudio de:

1. Todos los modelos de rol; masculino; el modelo paterno, el abuelo, los tíos...; los de rol femenino; la madre, nodriza, abuela, hermanas...

2. Los procesos identificatorios con las figuras importantes para construir su yo.

3. Las muertes y su influencia en su formación.

4. Las influencias familiares y sociales.

5. Los ideales incorporados a su yo.

6. La formación del aparato psíquico; Ello, Yo, Superyo.

7. Reactualización de sus conflictos infantiles por las circunstancias sociales actuales.

8. La elección de figuras heroicas ante la emergencia del motivo paterno-materno.

9. Las actitudes de gratificación para su ego.

10. Las representaciones sociales, elaboración de ideas.

11. El desarrollo de las relaciones de objeto a través de los procesos de incorporación, proyección e identificación.

12. Los ritos, mitos y tradiciones.

13. El discurso cotidiano y los proverbios. 
La difusión de la psicohistoria en la enseñanza en el ámbito universitario queda ampliamente demostrada a través del Curso de Psicohistoria, que el profesor David Beisel oferta desde 1976 en el Colegio Comunitario Rockland, de la Universidad Estatal de Nueva York, logrando convertirse en la materia de historia más popular de la Universidad, aún cuando la historia no es requisito curricular para los estudiantes que asisten a su curso.

El alto índice de aceptación desde luego que tiene que ver con elementos peculiares de la personalidad del profesor Beisel, pero también con la forma en que presenta el curso. Utiliza diferentes estrategias didácticas como son la lectura y películas, pero indiscutiblemente el soporte fundamental del curso son los contenidos que agrupa en cinco partes; introducción, historia de la infancia, psicobiografía, psicohistoria de grupos y Hitler y la Alemania nazi.

Considera que no es necesario tener estudios formales de Historia ni de Psicología, puesto que con la Introducción subsana la ausencia de esos conocimientos; además se nutre de las experiencias personales y la historia de cada participante de tal manera que, en poco tiempo el mismo grupo se convierte en un Laboratorio de Psicohistoria.

También, hoy la Psicohistoria se ha incorporado como una forma de escribir historia y son muchos los historiadores que la han hecho su estrategia metodológica en la investigación.

\section{Reflexiones finales}

La relación que tiene que ver con el engranaje entre el psiquismo y las configuraciones socio-culturales de la Historia, ha postulado diversas alternativas para su explicación; lo cual ha hecho que surjan una serie de metodologías que van desde la historia psicológica hasta la tendencia historiográfica conocida como Historia de las mentalidades, que la han llevado a considerar como la versión de esta corriente en Estados Unidos como Psicohistoria.

La psicohistoria vivió su auge en Europa y en Estados Unidos en la segunda mitad del siglo $\mathrm{XX}$, y es una explicación de la dinámica histórica en términos psicoanalíticos.

Actualmente cada vez son más los historiadores que consultan a psiquiatras o psicoanalistas o tienen como obligada referencia bibliográfica las obras de Freud para comprender más ampliamente los personajes que estudian.

También hoy la Psicohistoria se ha incorporado en las universidades como una forma de enseñar historia y son muchos los historiadores que la han hecho su estrategia metodológica. Sin embargo debemos advertir, que hacer psicohistoria no es meramente reducir la historia al psicoanalisis y éste a un apéndice de la historia, no olvidemos que tanto la historia como el psicoanálisis son teorías que no poseen el mismo grado de desarrollo y fundamentación científica, ambas poseen diferencias cualitativas esenciales de estructura; por lo cual debe entenderse como psicohistoria, la investigación que aprehende, describe y analiza a las diferentes figuras que el psiquismo ha adoptado históricamente en el interior de las múltiples y distintas configuraciones socio-culturales. Sólo hablamos de psicohistoria cuando se pone el énfasis en el análisis del inconsciente individual dentro del grupo social y dentro de un momento histórico específico; cuando estudiamos la incidencia o influencia de dicho psiquismo modelado históricamente. 
La estrategia psicohistórica debe ensayar la vía de doble camino; ir desde la comprensión de los modos como los individuos experimentarían psicológicamente sus condiciones históricas objetivas hasta la comprensión de la posible incidencia en la historia de dichas modulaciones psicológicas. .....claridad.....

A manera de conclusión podríamos afirmar que la expresión psicohistoria, lejos de referirse a una ciencia mínima cristalizada, es decir, a una metodología que hubiese organizado formalmente algún campo temático propio, recubre más bien una especie de nebulosa o constelación de problemas todos ellos de algún modo relacionados, es verdad, con la cuestión relativa a las posibles formas como el psiquismo humano puede engranar con la historia social y cultural...

Nos parece, por ello, que más que ofrecer una suerte de ecléctico o acaso escéptico catálogo informativo de semejantes intentos, lo que se impone es ensayar los vínculos que metodológicamente pueden darle al historiador el conocimiento del psicoanálisis y hablar más que de una amalgama de psico e historia, de una fértil interrelación entre la Historia y el Psicoanálisis; en esto no habría ni descalificación, reducción o rechazo sino una revisión crítica...y proponer que el estudio del hombre y de las sociedades se produce en ese doble circuito donde se conjugan dialécticamente las configuraciones histórico culturales y el psiquismo de los individuos.

De este modo insistiríamos proponiendo; que para evitar una suerte de malabarismo intelectual; entre historia y psicoanálisis, se considere a la psicohistoria como una estrategia teórico-metodológica, para la enseñanza y para la investigación de la historia y más que condensar en un término el campo científico de la historia y del psicoanálisis se vea la fertilidad de las relaciones que existen entre ambas disciplinas.

\section{NOTAS}

1 Para escribir del Pueblo, Michelet afirma, «...es necesario conocerlo, vivirlo, trabajarlo y sufrir con él, de este modo puede exponerse de su verdadera personalidad...Esta personalidad no la he captado de lo superficial, de sus aspectos pintorescos o dramáticos; no la he visto desde afuera, sino que la he experimentado desde dentro. [Ya que] ...quien se limite al examen del presente, a lo actual, nunca lo comprenderá. Quien se contente con ver lo exterior, con pintar la forma, no podrá siquiera verla, porque para verla realmente, para traducirla con fidelidad, es necesario saber lo que ella encubre. No hay pintura sin anatomía, p. 15.

2 Lucien Febvre, en Martín Lutero: un destino; aclara que su obra más que una biografía de Lutero es un juicio sobre Lutero, nada más. «Dibujar la curva de un destino que fue sencillo pero trágico; situar con precisión los pocos puntos verdaderamente importantes por los que pasó; mostrar cómo, bajo la presión de qué circunstancias, su impulso primero tuvo que amortiguarse y su trazo primitivo desviarse; plantear así, a propósito de un hombre de una singular vitalidad, el problema de las relaciones del individuo con la necesidad social...p. 9.

3 Febvre, op cit. p. 20.

4 Kantor ensaya desde coordenadas notablemente diferentes al psicoanálisis al utilizar en su psicología cultural, la dirección psicológíca interconductista.

5 Torres, Hugo. Cuerpo e Historia; Frida Kahlo. Ponencia presentada en el XLIII Congreso Nacional de Psicoanálisis; de la Asociación Psicoanalítica Mexicana. «El Cuerpo y el Psicoanálisis». Veracruz, Ver. 2003. 
La Psicohistoria: Método de enseñANZA, MÉtodo de INVESTIGACIÓN

\section{REFERENCIAS BIBLIOGRÁFÍCAS}

1. Bloch, M. (1993). Apologie pour l'histoire ou métier d'historien. Paris: Armand Colin Éditeur.

2. Certeau, M. (1995). Historia y psicoanálisis. México: Universidad Iberoamericana. ITESO.

3. _ (1993). La escritura de la Historia. México: Universidad Iberoamericana.

4. Chartier, R. (1999). El mundo como representación. España: Gedisa editorial.

5. Elías, N. (1982). La sociedad cortesana. México: Fondo de Cultura Económica.

6. Elliott, A. (1995). Teoría social y psicoanálisis en transición. Sujeto y sociedad de Freud a Kristeva. Argentina: Amorrortu editores.

7. Febvre, L. (1992). Martín Lutero: un destino. México: Fondo de Cultura Económica. (Breviarios: 113).

8. Foucault, M. (1986). Historia de la sexualidad. 1. La voluntad de saber. México: Siglo Veintiuno editores.

9. Siglo Veintiuno editores.

(1986). Historia de la sexualidad. 2. El uso de los placeres. México:

10. Freud, S. (1910). Un recuerdo infantil de Leonardo da Vinci.

11. (1913). Tótem y Tabú.

12. (1915). Lo Inconsciente.

13. (1927). El porvenir de una ilusión.

14. (1930). El malestar en la cultura. Argentina: Amorrortu editores.

15. Galende, E. (1992). Historia y repetición. Argentina: Editorial Paidós. (Psicología profunda).

16. Hornstein, L. (1993). Práctica psicoanalítica e Historia. Argentina: Editorial Paidós. (Psicología profunda).

17. Michelet, J. (1991). El Pueblo. México: Fondo de Cultura Económica. (Colección Popular, 445). 